\title{
Identification of the Epitope Recognized by the Anti-Red Sea Bream Iridovirus (RSIV) Monoclonal Antibody M10 Using a Phage Display RSIV Peptide Library
}

\author{
Tomokazu Takano ${ }^{1 *}$, Tomomasa Matsuyama ${ }^{1}$, Yasuhiko Kawato ${ }^{1}$, Takamitsu Sakai ${ }^{2}$, \\ Jun Kurita ${ }^{2}$, Yuta Matsuura ${ }^{1}$, Sachiko Terashima ${ }^{1}$, Kazuhiro Nakajima ${ }^{3}$ \\ and Chihaya Nakayasu ${ }^{1}$ \\ ${ }^{1}$ Nansei Main Station, National Research Institute of Aquaculture, Japan Fisheries Research \\ and Education Agency, Mie 519-0193, Japan \\ ${ }^{2}$ Tamaki Laboratory, National Research Institute of Aquaculture, Japan Fisheries Research \\ and Education Agency, Mie 519-0423, Japan \\ ${ }^{3}$ National Research Institute of Fisheries and Environment of Inland Sea, Japan Fisheries \\ Research and Education Agency, Hiroshima 739-0452, Japan
}

(Received June 17, 2019)

\begin{abstract}
Red sea bream iridoviral disease (RSIVD) spreads readily throughout the marine environment because of its wide variety of host species. Use of a rapid diagnostic method, such as the immunofluorescence antibody test, helps to control the disease, so the anti-RSIV monoclonal antibody M10 (mAb M10) has been developed in Japan. In the present study, we carried out epitope mapping using the phage display method to identify the antigen of mAb M10. A phage display RSIV peptide library was constructed to cover the entire genome of RSIV, then phage clones recognized by the antibody were selected by biopanning. The selected clones harbored partial fragments of the laminin-type epidermal growth factor-like domain (LEGFD) gene. N-terminal and C-terminal deletion peptides were then prepared from the amino acid sequence deduced from the smallest fragment to precisely determine the epitope. Finally, seven amino acids, EYDCPEY, located in the extracellular domain of the LEGFD protein were determined to be the epitope. Identical residues of the epitope were also identified from the LEGFD protein in other megalocytiviruses including the infectious spleen and kidney necrosis virus and turbot reddish body iridovirus. mAb M10 is considered to be widely available for the diagnostics of megalocytivirus infections.
\end{abstract}

Key words: mAb M10, epitope, Megalocytivirus, phage display library, red sea bream iridovirus, RSIV

Red sea bream iridoviral disease (RSIVD) was first recorded as causing mass mortality among farmed red sea bream (Pagrus major) in 1990 in Japan (Inouye et al., 1992). The disease has since spread to more than 30 species of marine fish, including the economically important species of yellowtail (Seriola quinqueradiata), greater amberjack (S. dumerili), sea bass (Lateolabrax japonicus), striped jack (Pseudocaranx dentex), and barred knifejaw (Oplegnathus fasciatus) (Kawakami and Nakajima, 2002; Matsuoka et al., 1996).

Similar viral diseases, caused by grouper iridovirus of Taiwan (TGIV) (Chao et al., 2004; Chou et al., 1998), infectious spleen and kidney necrosis virus (ISKNV) (He et al., 2000), rock bream iridovirus (Jung and Oh, 2000), and turbot reddish body iridovirus (TRBIV) (Shi et al.,

\footnotetext{
* Corresponding author

E-mail: takanoto@ fra.affrc.go.jp
}

2004), have been reported in Asian countries since the 1990s (Kurita and Nakajima, 2012). Currently, these viruses are classified into the genus Megalocytivirus, which has ISKNV as a type species in the family Iridoviridae (Jancovich et al., 2012). Three genetically distinct groups are known among the megalocytiviruses, including RSIV-, ISKNV-, and TRBIV-types, which are classified by the nucleotide sequence of the major capsid protein gene (Kurita and Nakajima, 2012). RSIVD caused by RSIV and ISKNV viruses is also listed by the World Organisation for Animal Health (OIE) (Kawato et al., 2017a).

Fish infected with RSIVD often have conspicuous respiratory movements because of severe anemia. Petechia in the gills, an enlarged spleen, the presence of a hemorrhagic exudate in the pericardial cavity, and pale internal organs are also commonly observed in diseased fish (Inouye et al., 1992). Multiple enlarged cells in the 
spleen, heart, kidney, and gills are the most typical histopathological change of RSIV-infected fish, and are utilized for the presumptive diagnosis of RSIVD by microscopic examinations of Giemsa-stained impression smears of the spleen (Kawato et al., 2017a).

The specific monoclonal antibody M10 (mAb M10) has been developed as an accurate diagnostic tool to identify RSIVD (Nakajima et al., 1995; Nakajima and Sorimachi, 1995). The indirect fluorescent antibody test (IFAT) using this antibody is listed in the OIE manual of Diagnostic Tests for Aquatic Animals (OIE, 2012) as a diagnostic method for RSIVD and is widely used in Japan (Kawakami and Nakajima, 2002; Kawato et al., 2017a; Matsuoka et al., 1996). However, the target of mAb M10 has not yet been determined, and only its size has been determined as within 180-230 kDa (Nakajima and Sorimachi, 1995).

mAb M10 was raised from Balb/c mice immunized with a cellular pellet prepared from the Bluegill fry-2 (BF2) cell line infected with RSIV (Nakajima and Sorimachi, 1995). The antibody detects different types of megalocytiviruses (RSIV and ISKNV), but does not react with other iridoviruses such as frog virus 3, epizootic haematopoietic necrosis virus, European sheatfish virus, and Singapore grouper iridovirus (Kawato et al., 2017b; Nakajima et al., 1998; Nakajima and Sorimachi, 1995). mAb M10 appears to recognize the antigen common to megalocytiviruses, but it is not clear whether this is present in RSIV alone or in viruses other than RSIV. Because RSVD is listed by the OIE, it is important to determine the target antigen of $\mathrm{mAb} M 10$ and to examine the range of viruses that can be detected by the antibody for use in diagnostic purposes.

Smith first established a technique for presenting polypeptides on the virion surface of filamentous phage (Smith, 1985). Since this pioneering work, the phage display technique has matured into a widely used method for selecting peptides and proteins with desired functions and properties from molecular libraries (Paschke, 2006). For instance, the technique is used to identify protein-ligand interactions, antibody engineering, and screening for receptor agonists or antagonists (Mullen et al., 2006). Further, in the medical field, the epitopes of neutralizing antibodies to $\mathrm{H} 5 \mathrm{~N} 1$ avian influenza virus have been characterized by epitope mapping using whole-genome fragment phage display libraries of the virus (Khurana et al., 2009). Hence, the phage display technique may also be utilized to determine the antigen recognized by $\mathrm{mAb} \mathrm{M} 10$.

In the present study, we generated a phage display RSIV peptide library harboring partial fragments of the RSIV genome, and determined the epitope of mAb M10 from phage clones selected from the library by affinity selection.

\section{Materials and Methods}

\section{Bacteria and viral strains}

Escherichia coli strain BLT5403 and strain BL21 (DE3) were used for phage display library construction and recombinant protein production, respectively. These bacterial strains were cultured with Luria-Bertani broth with appropriate antibiotics at $37^{\circ} \mathrm{C}$. RSIV strain RIE12-1 isolated from diseased red sea bream was used in this study (Matsuyama et al., 2018). The virus was inoculated into grunt fin (GF) cells (Clem et al., 1961) in $75-\mathrm{cm}^{2}$ flasks at $25^{\circ} \mathrm{C}$ with Eagle's basal medium (Gibco-BRL/Thermo Fisher Scientific) supplemented with $10 \%$ fetal bovine serum (Gibco-BRL/ Thermo Fisher Scientific), $100 \mathrm{lU} / \mathrm{ml}$ of penicillin, $100 \mu \mathrm{g} /$ $\mathrm{ml}$ streptomycin, $2 \mathrm{~mm}$ L-glutamine, and $25 \mathrm{~mm}$ HEPES. The medium was collected and centrifuged at 2,000 $\times g$ for 20 min after completion of the cytopathic effect. The supernatant containing the virus was stored in 1-ml aliquots at $-80^{\circ} \mathrm{C}$ and used for genomic DNA extraction.

\section{DNA extraction}

Virus genomic DNA was extracted using TNES urea buffer (Asahida et al., 1996) from $500 \mu \mathrm{L}$ of culture supernatant of RSIV-infected GF cells. The supernatant was mixed with $10 \times$ volume of TNES urea buffer containing Protease $\mathrm{K}(20 \mu \mathrm{g} / \mathrm{mL})$ and incubated for $12 \mathrm{~h}$ at $37^{\circ} \mathrm{C}$. The mixture was treated with an equal volume of phenol/chloroform/isoamyl alcohol (25:24:1) and centrifuged at $12,000 \times g$ at $4^{\circ} \mathrm{C}$ for $10 \mathrm{~min}$. DNA in the supernatant was precipitated with an equal volume of isopropanol, washed with $75 \%$ ethanol, then resuspended in nuclease-free water. The DNA sample was used for phage display library construction.

\section{Monoclonal antibody}

A hybridoma cell line producing mAb M10 that recognized RSIV-induced protein (Nakajima and Sorimachi, 1995) was cultured in $75-\mathrm{cm}^{2}$ flasks at $37^{\circ} \mathrm{C}$ with GIT medium (Wako) in a $5 \% \mathrm{CO}_{2}$ incubator to confluency. The medium was collected and centrifuged at 2,000 $\times g$ for $10 \mathrm{~min}$, then the supernatant was stored at $4^{\circ} \mathrm{C}$ with $0.01 \%$ sodium azide to inhibit bacterial growth.

\section{Construction of phage display RSIV peptide library}

Virus genomic DNA extracted from the supernatant of a culture of RSIV isolate RIE12-1 was used as the template for PCR amplification of entire regions of the virus genome using primers designed previously (Matsuyama et al., 2018). The PCR product was a fragment of around $6 \mathrm{~kb}$, with an approximately $1 \mathrm{~kb}$ overlap at each end. PCR amplification was performed using KOD-plus-neo DNA polymerase (Toyobo). The thermal profile consisted of initial denaturation at $98^{\circ} \mathrm{C}$ for $3 \mathrm{~min}$, followed by 40 cycles of denaturation of $98^{\circ} \mathrm{C}$ for $10 \mathrm{~s}$, annealing at and elongation at $68^{\circ} \mathrm{C}$ for $6 \mathrm{~min}$. 
The PCR products were electrophoresed on an agarose gel and extracted using a commercial kit (Promega). Equal amounts (100 ng) of extracted PCR products were mixed in a tube, sheared by a sonicator (Bioruptor UCD250; CosmoBio), and size-fractionated by agarose gel electrophoresis. DNA fragments within the range of 100-600 bp were excised from the gel by the Wizard SV gel and PCR clean-up system (Promega). Excised fragments were blunted and phosphorylated by T4 DNA polymerase (Takara) and T4 polynucleotide kinase (Takara), respectively. Next, a double-stranded oligonucleotide adapter (annealed oligonucleotides of BamHI_adapter_F 5'-phos-GGATCCAAGCAGTGGTAT CAACGCAGAGTA-3' and BamHI_adapter_R5'CTGCGTTGATACCACTGCTTGGATCC-3') was ligated to fragment termini. Adapter-ligated fragments underwent PCR amplification using a KAPA library amplification kit (KAPA Biosystems) with primer 5'-CTGCGTTGAT ACCACTGCTTGG-3'. The PCR amplicon was digested by $B a m \mathrm{H}$ I and ligated into the $B a m \mathrm{H}$ I site of vector T7Select 10-3b (Novagen) using the DNA ligation kit (Takara). The ligation reaction was subsequently packaged using T7Select packaging extract (Novagen), then propagated in E. coli strain BLT5403 to construct the primary library. This was inoculated into the brothcultured E. coli strain BLT5403 for amplification, and was stored at $-80^{\circ} \mathrm{C}$ with $8 \%$ glycerol until use.

\section{Biopanning}

Four rounds of biopanning were carried out to concentrate phage clones displaying peptides recognized by mAb M10. In the first round, $25 \mu \mathrm{L}$ of protein $\mathrm{G}$ mag sepharose (GE Healthcare) was equilibrated with Trisbuffered saline (TBS; $0.05 \mathrm{M}$ Tris, $0.15 \mathrm{M} \mathrm{NaCl}, \mathrm{pH} 7.6$ ) and incubated with $150 \mu \mathrm{L}$ of culture supernatant containing $\mathrm{mAb} \mathrm{M} 10$ at room temperature for $2 \mathrm{~h}$. After washing twice with TBS, sepharose beads were agitated with $1 \mu \mathrm{L}$ of the propagated phage display RSIV peptide library $\left(2.1 \times 10^{10}\right.$ plaque forming units $\left.[\mathrm{pfu}] / \mathrm{mL}\right)$ in $1 \mathrm{~mL}$ of TBST buffer $(0.05 \mathrm{~m}$ Tris, $0.15 \mathrm{M} \mathrm{NaCl}, 0.1 \%$ Tween 20, $\mathrm{pH} \mathrm{7.6)} \mathrm{at} \mathrm{room} \mathrm{temperature} \mathrm{for} 30 \mathrm{~min}$. The sepharose beads were extensively washed five times with TBST buffer, then bound phages were eluted with 200 $\mu \mathrm{L}$ of elution buffer (TBS containing $1 \%$ sodium dodecyl sulfate). The eluate was added to broth-cultured $E$. coli strain BLT5403 and propagated for the next round. Second and third rounds were carried out using the same process as the first round. To remove phages with non-specific binding after the third round, propagated phage clones were agitated with equilibrated beads without $\mathrm{mAb} \mathrm{M} 10$ at $4^{\circ} \mathrm{C}$ for $12 \mathrm{~h}$. The supernatant was collected, propagated again with broth-cultured E. coli strain BLT5403, and stored at $-80^{\circ} \mathrm{C}$ with $8 \%$ glycerol.

\section{Plaque lift assay}

Plaques were grown on a plastic petri dish $(80 \mathrm{~mm}$ in diameter) according to the manufacturer's protocol for T7Select 10-3b (Novagen). The dish was overlaid with a nitrocellulose membrane to transfer plaques, which was peeled off from the plate and allowed to air-dry. Blocking was conducted with TBS buffer containing 5\% skim milk for $1 \mathrm{~h}$ with gentle rocking. Subsequently, the mAb M10 culture supernatant was directly added to the blocking solution at a 1:100 dilution then incubated overnight at $4^{\circ} \mathrm{C}$. The membrane was washed with TBST buffer and incubated with a horseradish peroxidaseconjugated secondary goat anti-mouse IgG polyclonal antibody (1:1000) (SouthernBiotech) for $45 \mathrm{~min}$. The membrane was then washed three times with TBST, and the chemiluminescence signal was visualized with Clarity Western ECL substrate (Bio-Rad) and analyzed with an LAS-3000 luminescent image analyzer (Fujifilm) to select phage clones recognized by mAb M10. Nucleotide sequences of RSIV genomic DNA fragments in positive clones were determined with an $A B I$ prism 3130xl genetic analyzer (Applied Biosystems) using T7SelectUP primer 5'-GGAGCTGTCGTATTCCAGTC-3' and T7SelectDOWN primer $5^{\prime}$ - AACCCCTCAAGACCCG TTTA $-3^{\prime}$.

\section{Preparation of recombinant protein}

Nucleotide sequences of the inserts were aligned using Genetyx-ATGC version 4 (Genetyx Corporation) to generate a contig. An amino acid sequence containing the epitope of mAb M10 was predicted from the alignment and deduced amino acid sequence of the contig. A series of either $\mathrm{N}$-terminal or $\mathrm{C}$-terminal deletion peptides were then prepared to precisely determine the epitope of mAb M10. These deletion peptides were expressed as recombinant proteins fused with the trigger factor (TF) of E. coli. Detailed schemes of plasmid construction are shown in Fig. 1. First, the DNA fragment thought to encode the epitope was PCR-amplified from DNA extracted from a positive phage clone of the plaque lift assay. A linearized plasmid vector of pCold TF DNA (Takara) was also amplified by PCR. Both PCR products were then mixed and fused using the In-Fusion HD cloning kit (Clontech) to construct plasmid pColdepiM10. Subsequently, deletion mutants were generated by self-ligation of the PCR product amplified from pCold-epiM10 DNA template using PCR primers designed for respective deletions. KOD-plus-neo DNA polymerase (Toyobo) was used for the PCR reaction. All PCR primers used for plasmid preparation are listed in Table 1.

PCR products were phosphorylated by T4 polynucleotide kinase (Takara), then processed for self-ligation using T4 DNA ligase (Takara). The resulting plasmids were verified by DNA sequencing. Each plasmid was transfected into the host cell of E. coli strain BL21 (DE3), 


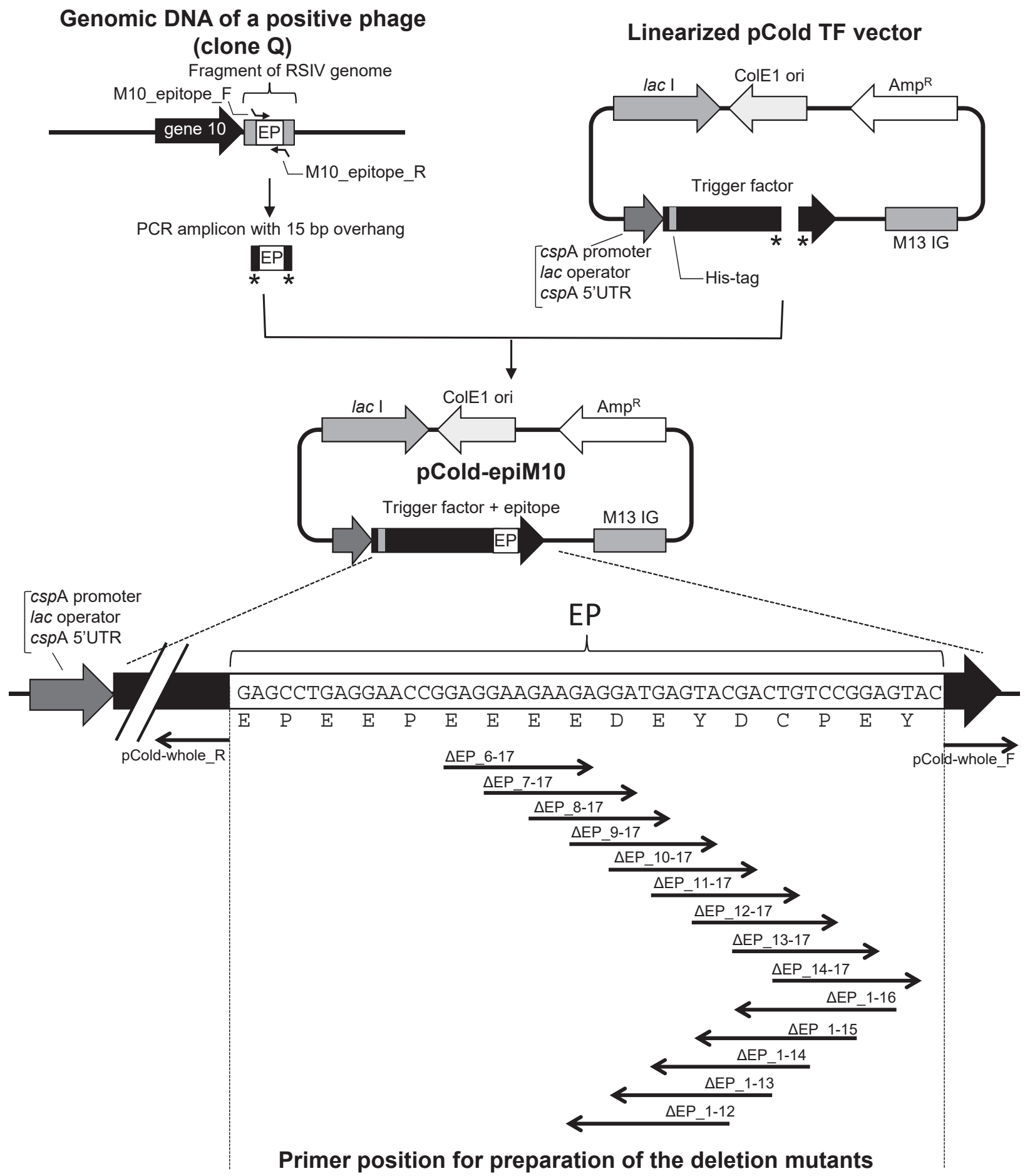

Fig. 1. Scheme of construction process for recombinant plasmids. A DNA fragment encoding a peptide of 17 amino acids presumed to contain the epitope (EP) was amplified by PCR from the DNA template prepared from clone Q. The PCR amplicon was inserted into the linearized pCold TF vector using the In-Fusion HD cloning kit to construct pCold-epM10. Deletion mutants were generated by self-ligation of the PCR product amplified from the pCold-epiM10 DNA template. PCR primers were designed to delete one residue at the $\mathrm{N}$-terminus or $\mathrm{C}$-terminus in order. A plasmid expressing the deleted recombinant peptide of interest was constructed by self-ligation of the PCR products amplified with each primer pair.

and the production of recombinant protein was induced by cold shock according to the manufacturer's protocol for pCold TF DNA (Takara). Host cells were harvested from culture media by centrifugation at $8,400 \times g$, resuspended in a buffer $\left(50 \mathrm{~mm} \mathrm{NaH}_{2} \mathrm{PO}_{4}, 300 \mathrm{~mm} \mathrm{NaCl}\right.$, $10 \mathrm{~mm}$ imidazole, $\mathrm{pH}$ 8.0), and lysed by ultrasonic disruption. Recombinant proteins were purified from supernatants of the lysate with Ni-NTA agarose (Qiagen) 
Table 1. Primers used for the preparation of recombinant proteins

\begin{tabular}{|c|c|c|}
\hline Primers & Sequence $\left(5^{\prime} \rightarrow 3^{\prime}\right)$ & Length (mer) \\
\hline \multicolumn{3}{|c|}{ Amplification of linearized pCold TF vector } \\
\hline pCold-TF_Ndel_F & TATGGAGCTCGGTACCCTCGAGGGATC & 27 \\
\hline pCold-TF_Ndel_R & TGCCTACCTTCGATACCACCACTACCGC & 28 \\
\hline \multicolumn{3}{|c|}{ Amplification of an epitope-encoding region from a positive phage (clone Q) } \\
\hline M10_epitope_F \# & TATCGAAGGTAGGCATGAGCCTGAGGAACCGGAG & 34 \\
\hline M10_epitope_R ${ }^{\#, *}$ & GTACCGAGCTCCATAttaGTACTCCGGACAGTCGTACTC & 39 \\
\hline \multicolumn{3}{|l|}{ N-terminal deletion } \\
\hline \multicolumn{3}{|l|}{ Forward } \\
\hline$\Delta \mathrm{EP} \_6-17$ & GAGGAAGAAGAGGATGAGTACGACTGTC & 28 \\
\hline$\Delta \mathrm{EP} \_7-17$ & GAAGAAGAGGATGAGTACGACTGTCCGG & 28 \\
\hline$\Delta \mathrm{EP} \_8-17$ & GAAGAGGATGAGTACGACTGTCCGGAG & 27 \\
\hline$\Delta E P \_9-17$ & GAGGATGAGTACGACTGTCCGGAGTAC & 27 \\
\hline$\Delta \mathrm{EP} \_10-17$ & GATGAGTACGACTGTCCGGAGTACTAATATG & 31 \\
\hline$\Delta$ EP_11-17 & GAGTACGACTGTCCGGAGTACTAATATGGAGC & 32 \\
\hline$\Delta E P_{-} \_12-17$ & TACGACTGTCCGGAGTACTAATATGGAGC & 29 \\
\hline$\Delta \mathrm{EP} \_13-17$ & GACTGTCCGGAGTACTAATATGGAGCTCGGT & 31 \\
\hline$\Delta \mathrm{EP} \_14-17$ & TGTCCGGAGTACTAATATGGAGCTCGGTAC & 30 \\
\hline \multicolumn{3}{|c|}{ Reverse (specific to pCold TF) } \\
\hline pCold-whole_R & ATGCCTACCTTCGATACCACCACTACC & 27 \\
\hline \multicolumn{3}{|c|}{ C-terminal deletion } \\
\hline \multicolumn{3}{|c|}{ Forward (specific to pCold TF) } \\
\hline pCold-whole_F * & taaTATGGAGCTCGGTACCCTCGAGG & 26 \\
\hline \multicolumn{3}{|l|}{ Reverse } \\
\hline$\Delta \mathrm{EP} \_1-16$ & CTCCGGACAGTCGTACTCATCCTCTTCTT & 29 \\
\hline$\Delta E P_{-} 1-15$ & CGGACAGTCGTACTCATCCTCTTCTTCC & 28 \\
\hline$\Delta \mathrm{EP}_{-} 1-14$ & ACAGTCGTACTCATCCTCTTCTTCCTCCG & 29 \\
\hline$\Delta \mathrm{EP}_{-} 1-13$ & GTCGTACTCATCСTCTTCTTCCTCCGG & 27 \\
\hline$\Delta \mathrm{EP}_{-}{ }^{-} 1-12$ & GTACTCATCСTCTTCTTCСTCCGG & 24 \\
\hline
\end{tabular}

\# Underlined section indicates the 15 base overhangs for the In-Fusion HD cloning kit.

* Stop codons are shown in lower case.

by a batch method. Recombinant proteins were quantified using a commercially available Bradford protein assay kit (Bio-Rad). A total of $200 \mathrm{ng}$ of each recombinant protein was diluted in a commercial sample buffer (EZApply; Atto), boiled for $5 \mathrm{~min}$, then loaded on a $15 \%$ sodium dodecyl sulfate polyacrylamide gel. Gels were blotted on a transfer membrane (Clear Blot Membrane-P; Atto), and protein was detected using mAb M10 and AP-conjugated anti-mouse IgG secondary antibody (BioRad) with BCIP/NBT alkaline phosphatase substrate (Moss, Inc.). Essential amino acids in the epitope were determined from positive signals of the deletion peptides.

\section{Results}

Size of phage display RSIV peptide library

A randomized RSIV peptide library was constructed in the T7 phage-derived vector T7Select 10-3b. The diversity of library inserts was checked by sequencing with 16 phage clones randomly selected from the primary library. All clones had inserts identical to the nucleotide sequence of the RSIV genome, and each insert had a different sequence confirming the diversity of this library. The average insert size was estimated from the sequencing result and was approximately 300 bp. The primary library was estimated to contain $3.2 \times$ $10^{6}$ independent phage clones. After amplification of the primary library, the titer reached $2.1 \times 10^{10} \mathrm{pfu} / \mathrm{mL}$.

\section{Screening of randomized RSIV peptide library}

Enrichment of M10-reactive phage clones after four rounds of biopanning was confirmed by the plaque lift assay (Fig. 2). A total of 17 phage clones showing strong signals were randomly selected and subjected to DNA sequencing. As a result, fifteen (15) independent sequences were found from the 17 phage clones (Fig. 3A). The sizes of these RSIV-derived DNA fragment inserts ranged from $87-353 \mathrm{bp}$, and each fragment was confirmed to be in-frame with gene 10B on the T7Select $10-3 b$ vector. Nucleotide sequences of these fragments were assembled into a single contig (Fig. 3A), which was 879 bp and encoded 292 amino acid residues. Among the 17 phage clones, clone $\mathrm{Q}$ harbored the smallest DNA insert, encoding a peptide of 28 amino acid residues (TTTTTVAPTEPEPEEPEEEEDEYDCPEY);

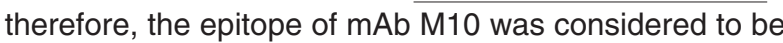
contained in this peptide. The same sequence as the 

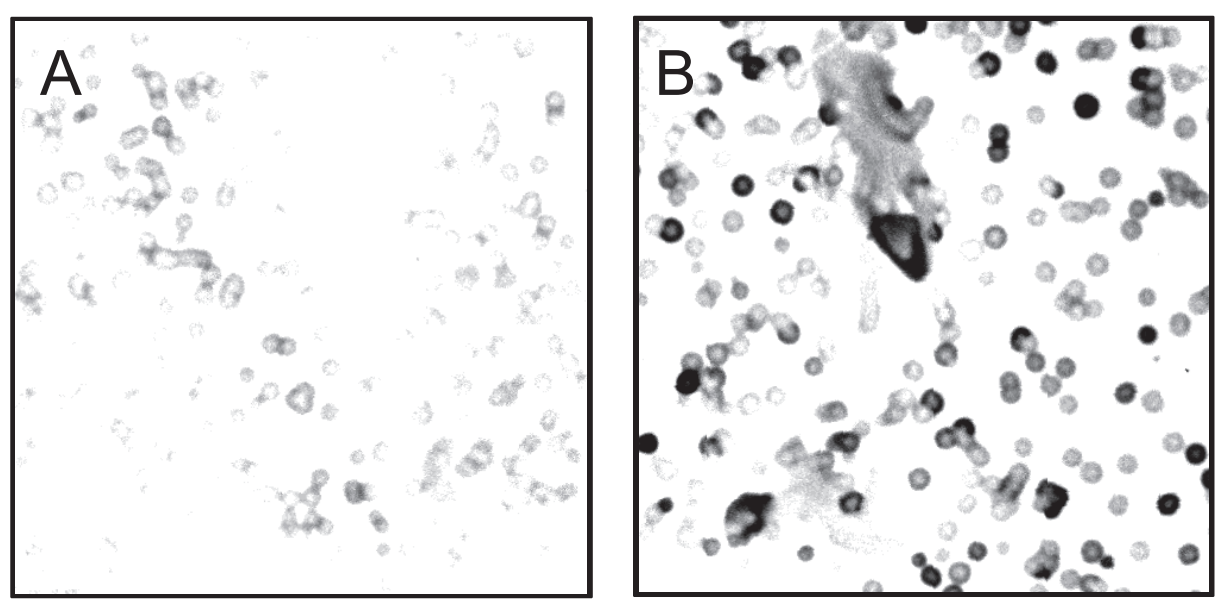

Fig. 2. Confirmation of the feasibility of biopanning. A number of plaques (phage clones) showed an intense signal after biopanning with mAb M10. Panel A shows the original stock of the phage display RSIV peptide library. Panel B shows phage clones after biopanning.

17 amino acid residues underlined was found in four copies from the deduced amino acid sequence of the contig (Fig. 3B). Further, all 17 selected clones were found to encode this 17 amino acid motif. This may explain why 17 phage clones were recognized by mAb M10 although some had inserts that did not overlap the contig (e.g., clones A and Q) (Fig. 3A).

We further analyzed this 17-residue peptide (epiM10 ${ }_{1-17}$, EPEEPEEEEDEYDCPEY) to precisely determine the epitope of $\mathrm{mAb}$ M10. A chimeric protein consisting of TF at the N-terminus and epiM10 ${ }_{1-17}$ at the $\mathrm{C}$-terminus and its deletion mutants were successfully prepared using the pCold TF expression system in $E$. coli (Fig. 4). Among the recombinant proteins, $\Delta$ epiM10 ${ }_{11-17}$ lacking 10 amino acid residues at the $\mathrm{N}$-terminal of epiM10 ${ }_{1-17}$ was detected without decrement of the signal intensity by western blot analysis. Conversely, the recombinant protein with a deletion of one amino acid ( $\Delta$ epiM10 $\left.{ }_{1-16}\right)$ at the C-terminus lost reactivity with mAb M10 (Fig. 4). This indicated that the epitope of this antibody consisted of seven amino acids: EYDCPEY.

Determination and analysis of the antigenic gene of mAb M10

A total of 108 open reading frames were predicted on the genome of RIE12-1 (GenBank accession no. AP017456). The nucleotide sequence of the contig generated from the positive phage clones was identical to the partial sequence of the laminin-type epidermal growth factor-like domain (LEGFD) gene of RIE12-1 (GenBank accession no. BAZ95658). A peptide sequence identical to the mAb M10 epitope was found in the LEGFD protein but not from other proteins of RIE121 , suggesting that LEGFD is the sole target of $\mathrm{mAb} M 10$ among RSIV proteins. Of note, the peptide sequence of the epitope is conserved in LEGFD proteins of closely related species to RSIV, such as ISKNV (GenBank accession no. AAL98747) and TRBIV (GenBank accession no. ADE34369). LEGFD proteins of these megalocytiviruses are type I membrane proteins sharing $68 \%-$ $72 \%$ amino acid identity, and they have a characteristic region of 8-9 EGF-like domains (Fig. 5). The repetitive region, containing multiple copies of the amino acid sequence represented by PTEXEPEXPXEEEDEYD CPEYEDxxITSAPPTTXPPPKREC, was also found in the LEGFD proteins. The epitope of $\mathrm{mAb} M 10$ is therefore contained within this repeat region, which is adjacent to the N-terminal EGF-like domain site (Fig. 5). The LEGFD protein of RSIV, ISKNV, and TRBIV contains four, two, and three copies of the repeat, resulting in the existence of multiple epitopic sites within one molecule of the LEGFD protein (Fig. 5).

\section{Discussion}

The size and complexity of a phage display library is important for unbiased epitope mapping. The phage display RSIV peptide library constructed in this study had a titer of $3.2 \times 10^{6}$ independent phage clones with an average insert size of $300 \mathrm{bp}$. Because the RSIV RIE $12-1$ genome is around $113 \mathrm{~kb}$ in size, this library provides 8500 -fold coverage of the virus. Therefore, it is sufficient to cover the entire RSIV RIE12-1 genome. The complexity of the library was also considered to be adequate for epitope mapping. At least 15 independent types of clones containing epitope-coding DNA fragments of the RSIV genome were found in this library by biopanning with $\mathrm{mAb}$ M10.

We found that the epitope of mAb M10 was present in the LEGFD protein of RSIV RIE12-1, and calculated its molecular weight as $113 \mathrm{kDa}$ from the deduced amino acid sequence. However, the target molecule immunoprecipitated from RSIV-infected BF-2 cells in a previous study was reported to be $180-230 \mathrm{kDa}$, and the molecule showed heterogenous electrophoretic mobility 
A

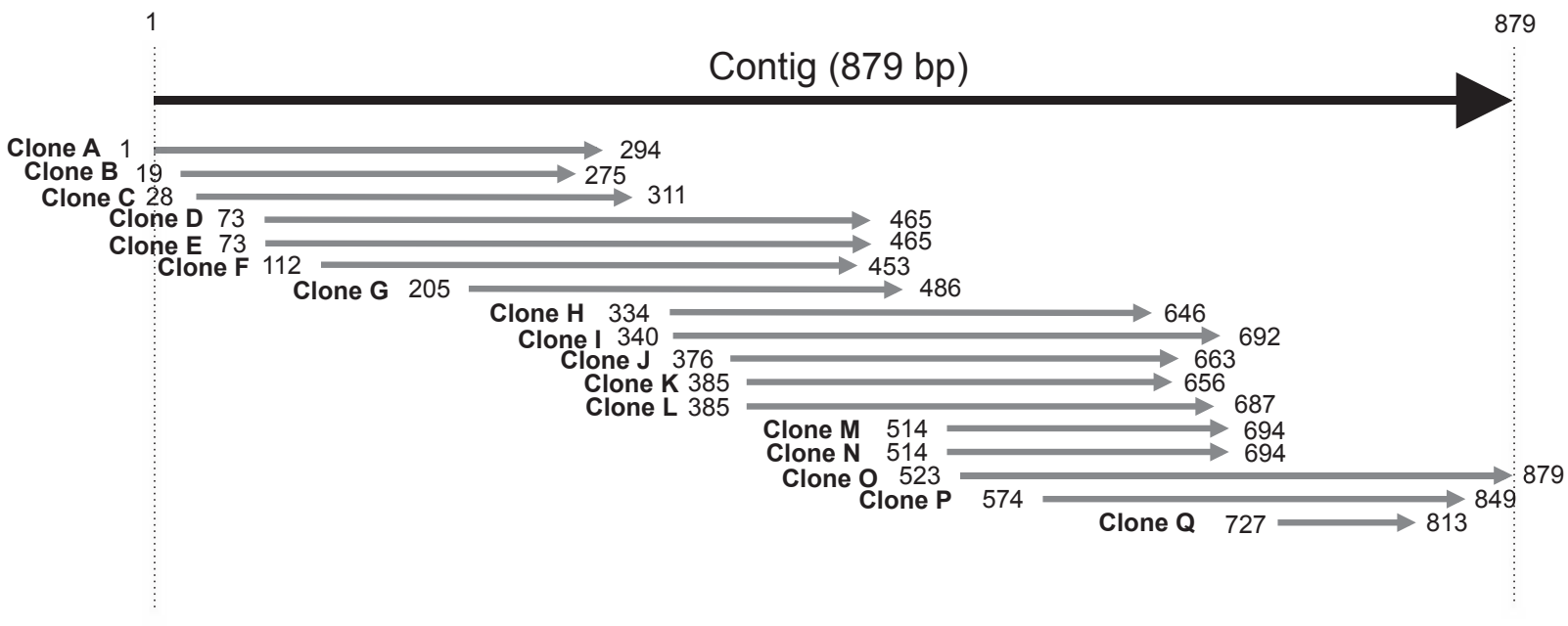

B

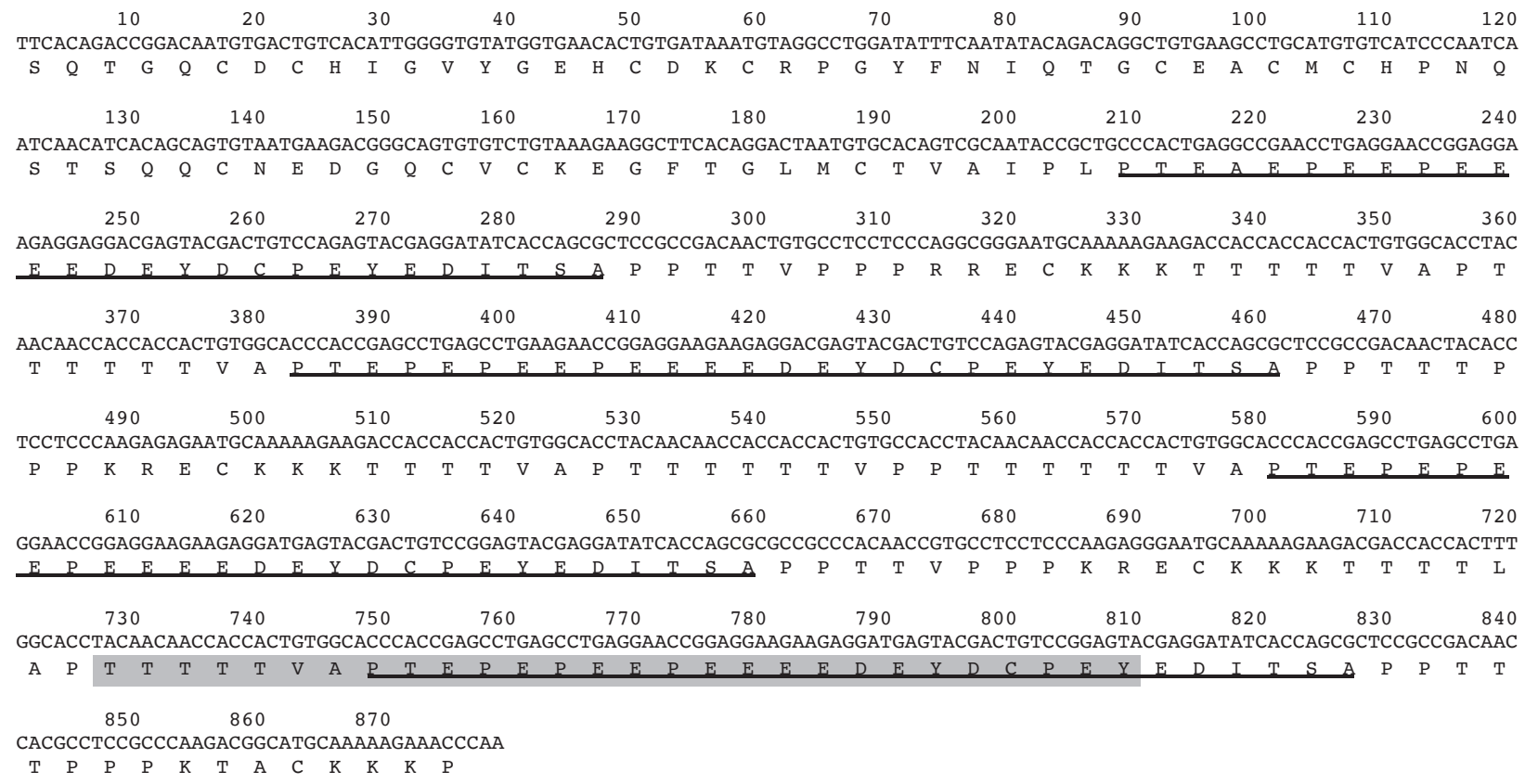

Fig. 3. A contig assembled from the insert sequences of positive phage clones. Nucleotide sequences from a total of 17 clones (clones $\mathrm{A}-\mathrm{Q}$ ) were aligned to generate an $879 \mathrm{bp}$ contig. Clones $\mathrm{E}$ and $\mathrm{D}$ and clones $\mathrm{M}$ and $\mathrm{N}$ contain the same inserts, so there are a total of 15 unique inserts. A) All fragments were confirmed to be in-frame in the contig (arrows) which encodes a partial sequence of the LEGFD gene. B) The repetitive region harboring four copies of the distinctive amino acid sequence represented by PTEP (or A) EPEEPEEEEDEYDCPEYEDITSA (underlined) was identified from the deduced amino acid sequence of the contig. Twenty-eight amino acid residues encoded by clone $Q$ are highlighted by the shaded box.

(Nakajima and Sorimachi, 1995). Six potential $\mathrm{N}$-glycosylation sites were predicted from the amino acid sequence of the LEGFD protein in RSIV using the NetNGlyc 1.0 Server (http://www.cbs.dtu.dk/services/ NetNGlyc/) (data not shown). Hence, glycosylation is the most compelling explanation for the difference between the measured and estimated molecular weights of the LEGFD protein. Further analysis is needed to clarify these observations.

The amino acid sequence of the epitope (EYDCPEY) was identified from only the LEGFD protein when whole proteins encoded in the RSIV RIE12-1 


\title{
N-terminal deletion
}

\author{
Lanes \\ 1: epiM10 $1-17$ \\ 2: $\Delta \operatorname{epiM10} 6-17$ \\ 3: $\Delta$ epiM10 $1-17$ \\ 4: $\Delta \operatorname{epiM10} 0_{8-17}$ \\ 5: $\Delta$ epiM10 \\ 6: $\Delta$ epiM10 $10-17$ \\ 7: $\Delta$ epiM10 $11-17$ \\ 8: $\Delta$ epiM10 $12-17$ \\ 9: $\Delta$ epiM10 $13-17$ \\ 10: $\Delta$ epiM10 $14-17$
}

Schematic diagram of recombinant proteins
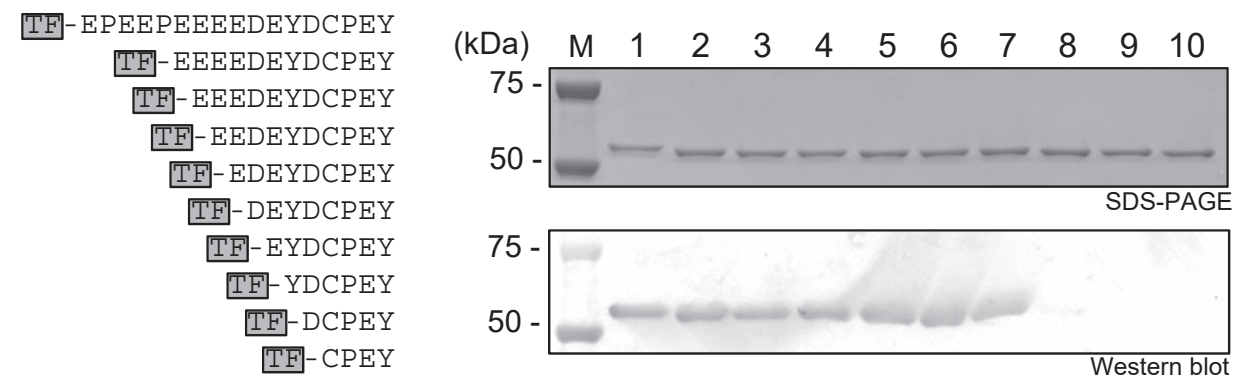

\section{C-terminal deletion}
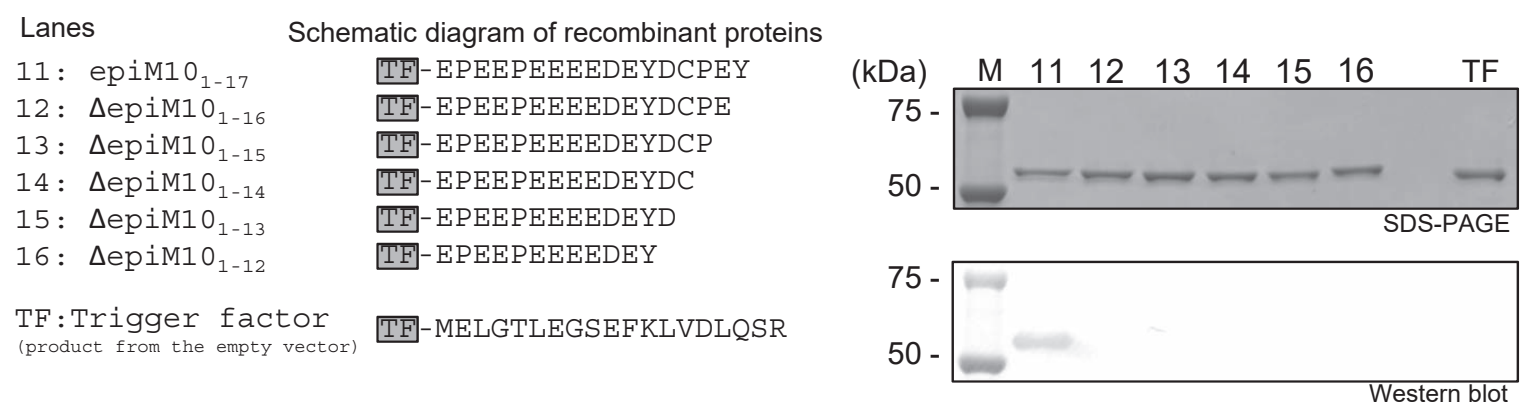

Fig. 4. Western blot analysis of recombinant proteins expressed from the deletion mutants of pCold-epiM10. Recombinant proteins of $\Delta$ epiM10 ${ }_{12-17}$ and $\Delta$ epiM10 ${ }_{1-16}$ showed a marked loss of reactivity to mAb M10.

genome were surveyed. Interestingly, the LEGFD protein harbors multiple epitope sites, suggesting that one molecule of LEGFD protein would be recognized by multiple numbers of $\mathrm{mAb} M 10$. This property may increase the signal intensity of the mAb M10-based detection of LEGFD protein in western blot analysis and IFAT. Moreover, the LEGFD homolog is well conserved among megalocytivirus species, including ISKNV, RSIV, and TRBIV, while no homolog has been found in other viral species. LEGFD proteins in ISKNV and TRBIV also have multiple epitope sites, so mAb M10 is thought to detect a broad range of megacycloviruses, and it is compelling that mAb M10 is cross-reactive to ISKNV. Although mAb M10 is expected to respond to TRBIV, it will be necessary to test the reactivity of TRBIV isolates in future studies.

RSIV-infected cells were previously identified by the presence of diffuse staining throughout the cell by an immunofluorescent assay with mAb M10 (Kurita and Nakajima, 2012). The RSIV LEGFD protein was determined to be a type I membrane protein from its deduced amino acid sequence, while the VP23R protein (LEGFD protein of ISKNV) was shown to be expressed on the plasma membrane of ISKNV-infected cells and cannot be a viral envelope protein (Xu et al., 2010). Thus, we consider that mAb M10 is an antibody for detecting protein expressed only on virus-infected cells rather than viral particles. Further, a unique function of VP23R has been reported in previous studies (Xu et al., 2010; Xu et al., 2014). VP23R interacts with nidogen-1 to play a pivotal role in the attachment of infected cells by lymphatic endothelial cells. This phenomenon was speculated to be an immune evasion strategy adopted by megalocytiviruses to effectively shield infected cells from host immune attack before virion maturation (Xu et al., 2014). On the other hand, regarding the function of LEGFD of RSIV, since LEGFD gene expression occurs late in infection, the gene has only been reported to be a late gene (Described as ORF291L by Lua et al., 2005). Therefore, as well as the diagnosis of megalocytivirus infections, mAb M10 could be utilized in further study of the LEGFD protein function in terms of host-pathogen interactions during RSIV infection.

In conclusion, we characterized the binding epitope of mAb M10 used for the diagnosis of RSIVD in Japan. This antibody is directed against seven amino acid residues within an uncharacterized repeat region of the LEGFD protein. Further, the epitopic regions are conserved in LEGFD proteins of megalocytiviruses such as RSIV, ISKNV, and TRBIV. This antibody could be widely used to diagnose infection by a member of the megalocytivirus. 


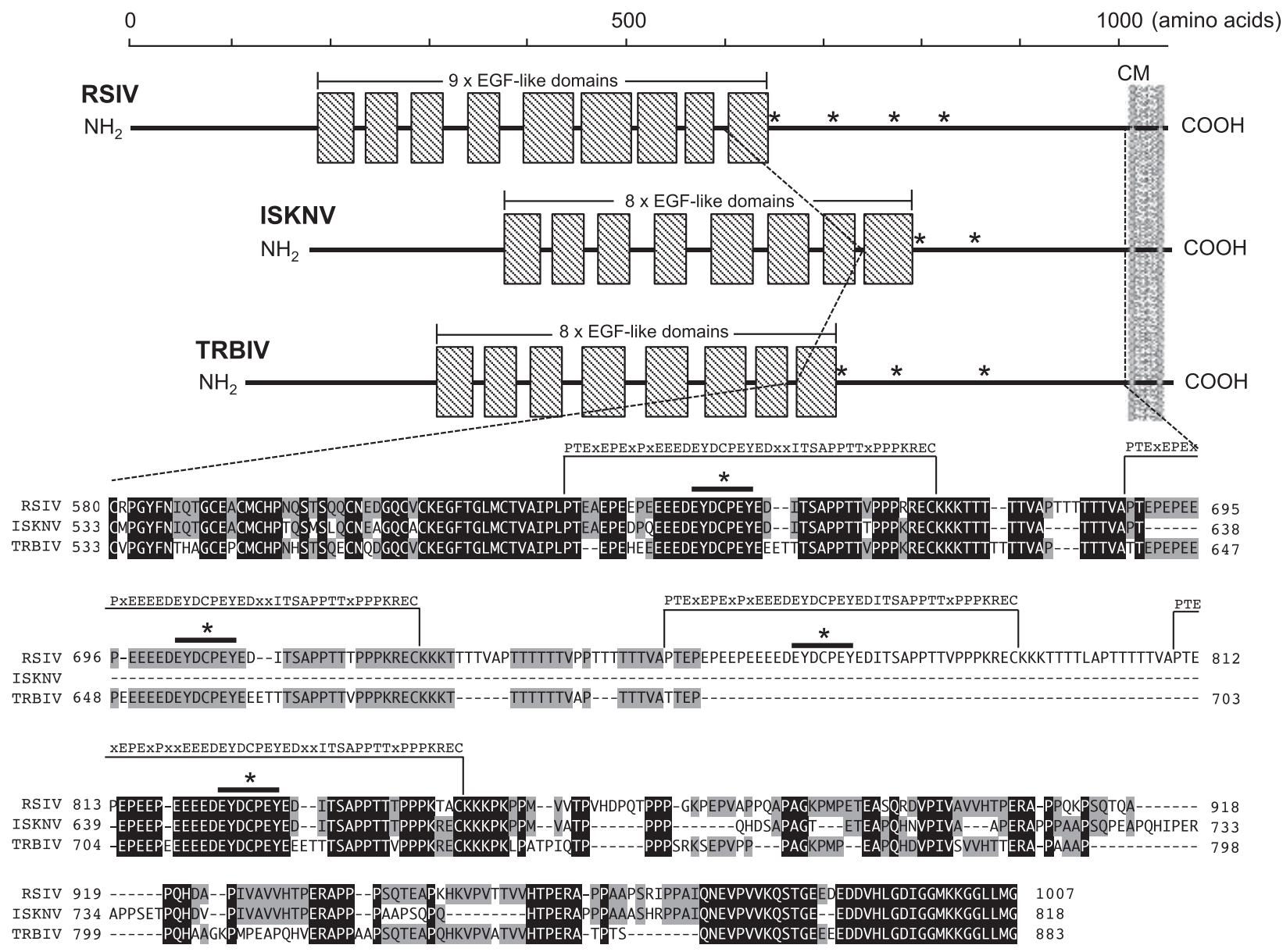

Fig. 5. Schematic of LEGFD proteins of megalocytiviruses. LEGFD proteins have 8-9 EGF-like domains in their extracellular domains. The epitopes (asterisks) of mAb M10 are also located outside the cellular membrane (CM), and are flanked by the EGF-like domain site at the N-terminal side. Alignment of the amino acid sequences of epitopic regions between RSIV, ISKNV, and TRBIV is shown. Identical residues between the three viral species are shaded in black, and identical residues between two species are shaded in gray. Gaps are highlighted by a dashed line. The domains on LEFGD proteins were predicted by SMART (Schultz et al., 1998).

\section{Acknowledgement}

This work was supported in part by a JSPS KAKENHI Grant-in-Aid for Exploratory Research number 16K14977 from the Ministry of Education, Culture, Sports, Science and Technology.

\section{References}

Asahida, T., T. Kobayashi, K. Saitoh and I. Nakayama (1996): Tissue preservation and total DNA extraction form fish stored at ambient temperature using buffers containing high concentration of urea. Fish. Sci., 62, 727-730.

Chao, C. B., C. Y. Chen, Y. Y. Lai, C. S. Lin and H. T. Huang (2004): Histological, ultrastructural, and in situ hybridization study on enlarged cells in grouper Epinephelus hybrids infected by grouper iridovirus in Taiwan (TGIV). Dis. Aquat. Organ., 58, 127-142.

Chou, H., C. Hsu and T. Peng (1998): Isolation and characterization of a pathogenic iridovirus from cultured grouper (Epinephelus sp.) in Taiwan. Fish Pathol., 33, 201-206.

Clem, L. W., L. Moewus and M. Michael Sigel (1961): Studies with cells from marine fish in tissue culture. Proc. Soc. Exp. Biol. Med., 108, 762-766.

He, J. G., S. P. Wang, K. Zeng, Z. J. Huang and S. M. Chan (2000): Systemic disease caused by an iridovirus-like agent in cultured mandarinfish, Siniperca chuatsi (Basilewsky), in China. J. Fish Dis., 23, 219-222.

Inouye, K., K. Yamano, Y. Maeno, K. Nakajima, M. Matsuoka, Y. Wada and M. Sorimachi (1992): Iridovirus infection of cultured red sea bream, Pagrus major. Fish Pathol., 27, 19-27.

Jancovich, J. K., V. G. Chinchar, A. Hyatt, T. Miyazaki and Q. Y. Zhang (2012): Family Iridoviridae. In: A. M. Q. King, M. J. Adams, E. B. Carstens and E. J. Lefkowitz (eds) Virus Taxonomy: Ninth Report of the International Committee on Taxonomy of Viruses. Elsevier/Academic Press, London/Waltham, Massachussetts/San Diego, California, pp. 193-210.

Jung, S. and M. Oh (2000): Iridovirus-like infection associated with high mortalities of striped beakperch, Oplegnathus fasciatus (Temminck et Schlegel), in southern coastal areas of the Korean peninsula. J. Fish Dis., 23, 223-226.

Kawakami, H. and K. Nakajima (2002): Cultured fish species affected by red sea bream iridoviral disease from 1996 to 
2000. Fish Pathol., 37, 45-47.

Kawato, Y., J. Kurita and K. Nakajima (2017a): Red Sea Bream Iridoviral Disease. Fish Pathol., 52, 57-62.

Kawato, Y., H. Yamashita, K. Yuasa, S. Miwa and K. Nakajima (2017b): Development of a highly permissive cell line from spotted knifejaw (Oplegnathus punctatus) for red sea bream iridovirus. Aquaculture, 473, 291-298.

Khurana, S., A. L. Suguitan, Y. Rivera, C. P. Simmons, A. Lanzavecchia, F. Sallusto, J. Manischewitz, L. R. King, K. Subbarao and H. Golding (2009): Antigenic fingerprinting of H5N1 avian influenza using convalescent sera and monoclonal antibodies reveals potential vaccine and diagnostic targets. PLoS Med, 6, e1000049.

Kurita, J. and K. Nakajima (2012): Megalocytiviruses. Viruses, 4, 521-538.

Lua, D. T., M. Yasuike, I. Hirono and T. Aoki (2005): Transcription program of red sea bream iridovirus as revealed by DNA microarrays. J. Virol., 79, 15151-15164.

Matsuoka, S., K. Inouye and K. Nakajima (1996): Cultured fish species affected by red sea bream iridoviral disease from 1991 to 1995. Fish Pathol., 31, 233-234.

Matsuyama, T., N. Sano, T. Takano, T. Sakai, M. Yasuike, A. Fujiwara, Y. Kawato, J. Kurita, K. Yoshida, Y. Shimada and C. Nakayasu (2018): Antibody profiling using a recombinant protein-based multiplex ELISA array accelerates recombinant vaccine development: Case study on red sea bream iridovirus as a reverse vaccinology model. Vaccine, 36, 2643-2649.

Mullen, L. M., S. P. Nair, J. M. Ward, A. N. Rycroft and B. Henderson (2006): Phage display in the study of infectious diseases. Trends Microbiol., 14, 141-147.

Nakajima, K., Y. Maeno, M. Fukudome, Y. Fukuda, S. Tanaka S. Matsuoka and M. Sorimachi (1995): Immunofluorescence test for the rapid diagnosis of red sea bream iridovirus infection using monoclonal antibody. Fish Pathol., 30, 115-119.

Nakajima, K., Y. Maeno, K. Yokoyama, C. Kaji and S. Manabe (1998): Antigen analysis of red sea bream iridovirus and comparison with other fish iridoviruses. Fish Pathol., 33, 73-78.

Nakajima, K. and M. Sorimachi (1995): Production of monoclonal antibodies against red sea bream iridovirus. Fish Pathol., 30, 47-52.

OIE (2012): Red sea bream iridoviral disease. In: Manual of Diagnostic Tests for Aquatic Animals 2012. World Organisation for Animal Health, Paris, pp. 345-356.

Paschke, M. (2006): Phage display systems and their applications. Appl. Microbiol. Biotechnol., 70, 2-11.

Schultz, J., F. Milpetz, P. Bork and C. P. Ponting (1998): SMART, a simple modular architecture research tool: identification of signaling domains. Proc. Natl. Acad. Sci. USA, 95, 5857-5864.

Shi, C., Y. Wang, S. Yang, J. Huang and Q. Wang (2004): The first report of an iridovirus-like agent infection in fanned turbot, Scophthalmus maximus, in China. Aquaculture, 236, 11-25.

Smith, G. P. (1985): Filamentous fusion phage: novel expression vectors that display cloned antigens on the virion surface. Science, 228, 1315-1317.

Xu, X., S. Weng, T. Lin, J. Tang, L. Huang, J. Wang, X. Yu, L. Lu, Z. Huang and J. He (2010): VP23R of infectious spleen and kidney necrosis virus mediates formation of virusmock basement membrane to provide attaching sites for lymphatic endothelial cells. J. Virol., 84, 11866-11875.

Xu, X., M. Yan, R. Wang, T. Lin, J. Tang, C. Li, S. Weng and J. G. He (2014): VP08R from infectious spleen and kidney necrosis virus is a novel component of the virus-mock basement membrane. J. Virol., 88, 5491-5501. 